F. Boomsma $\cdot$ U. Pedersen-Bjergaard •

B. Agerholm-Larsen · H. Hut · S. S. Dhamrait •

B. Thorsteinsson - A. H. van den Meiracker

\title{
Association between plasma activities of semicarbazide-sensitive amine oxidase and angiotensin-converting enzyme in patients with type 1 diabetes mellitus
}

Received: 8 September 2004 / Accepted: 3 December 2004 / Published online: 14 April 2005

(C) Springer-Verlag 2005

\begin{abstract}
Aims/hypothesis: Plasma semicarbazide-sensitive amine oxidase (SSAO) is elevated in patients with type 1 and type 2 diabetes and has been implicated in the pathophysiology of diabetic late complications. The regulation of SSAO production remains unknown. We studied correlations between plasma SSAO activity and parameters associated with diabetic late complications. Methods: Plasma SSAO was measured in a well-characterised group of 287 patients with type 1 diabetes. Standard statistical methods were used to investigate correlations with clinical parameters and components of the renin-angiotensin system. Results: Overall, plasma SSAO was elevated, at $693 \pm 196$ $\mathrm{mU} / 1$ (mean $\pm \mathrm{SD}$; normal controls $352 \pm 102 \mathrm{mU} / \mathrm{l}$ ). Plasma SSAO was higher in the group with late complications or hypertension, and in patients treated with ACE-inhibitors. In univariate analysis a significant positive correlation $(p<0.001, r=0.27)$ was found between plasma SSAO and serum ACE activity in patients untreated with ACE inhibitors or angiotensin II receptor antagonists $(n=221)$, but plasma SSAO did not differ by $A C E I / D$ genotype. Plasma SSAO correlated positively with duration of diabetes,
\end{abstract}

F. Boomsma $(\bowtie) \cdot$ H. Hut $\cdot$ A. H. van den Meiracker Department of Internal Medicine, Erasmus MC,

Room Bd-234, Dr. Molewaterplein 40,

3015 GD Rotterdam, The Netherlands

e-mail: f.boomsma@erasmusmc.nl

Tel.: +31-10-4633764

Fax: +31-10-4634531

U. Pedersen-Bjergaard · B. Thorsteinsson

Department of Internal Medicine F, Hillerød Hospital,

Hillerød, Denmark

B. Agerholm-Larsen

Department of Clinical Biochemistry,

Herlev University Hospital,

Herlev, Denmark

\section{S. S. Dhamrait}

Department of Cardiovascular Genetics,

University College London,

London, UK
$\mathrm{HbA}_{1} \mathrm{c}$ and plasma renin, and negatively with plasma angiotensinogen and body mass index. A multiple regression analysis including these variables resulted in serum ACE activity $(p<0.001), A C E$ genotype (negatively, $p<0.001)$ and $\mathrm{HbA}_{1} \mathrm{c}(p=0.023)$ as explaining variables. Conclusions/ interpretation: Results suggest that a common factor is involved in the regulation of both plasma SSAO and serum ACE, which is different from the genetic determination of ACE activity.

Keywords Angiotensin-converting enzyme ·

Diabetes type 1 . Late complications - Polymorphism . Renin-angiotensin system - Semicarbazide-sensitive amine oxidase

Abbreviations ACEI: angiotensin-converting enzyme inhibitor - ARB: angiotensin receptor blocker - AT1R: angiotensin II receptor subtype 1 - AT2R: angiotensin II receptor subtype 2 - CaCB: calcium channel blocker . RAS: renin-angiotensin system - SSAO: semicarbazidesensitive amine oxidase - VAP-1: vascular adhesion protein 1

\section{Introduction}

Semicarbazide-sensitive amine oxidase (SSAO) is an enzyme widely present in nature. In man, a membranebound form is abundantly present in vascular endothelial and smooth muscle cells and in adipocytes, while a soluble form circulates in plasma (for a recent review, see [1]).

SSAO appears to have multiple functions. As an enzyme it can transform exogenous primary amines like allylamine and benzylamine, and endogenous amines like methylamine and aminoacetone, into the corresponding aldehydes, at the same time generating hydrogen peroxide and ammonia. These products are all (cyto)toxic. Furthermore, it was recently discovered that vascular adhesion protein-1 (VAP-1), which is involved in the extravasation of leucocytes, is identical to SSAO [2]. An increasing body of 
mainly experimental evidence links SSAO to vascular damage, formation of AGE, linkage of proteins to form insoluble products, atherosclerosis and oxidative stress $[1,3-5]$. On the other hand, SSAO is involved in the recruitment of the glucose transporter GLUT4 to the cell membrane through local formation of the signalling molecule hydrogen peroxide [6]. Thus, SSAO, together with a suitable substrate, can mimic the action of insulin and increase glucose uptake.

Plasma SSAO is probably derived from the membranebound form [7-9] and its activity normally seems to be well regulated within a relatively small range. It is not yet known which factors are involved in the regulation. However, circulating SSAO has been found to be elevated in type 1 and type 2 diabetes [10-13], in the former already at the time of diagnosis. The mechanism behind the elevation of plasma SSAO in diabetes is not known.

We hypothesised that by investigating correlations of plasma SSAO activity with other factors involved in the pathophysiology of diabetes and its late complications, we might find clues about the regulatory mechanisms. One such factor is the renin-angiotensin system (RAS). Although some parameters of the RAS (renin and angiotensin II) do not appear to be elevated in diabetes [14], some others are. Thus, serum ACE activity is increased in patients with diabetes aggravated by late complications, while the risk of severe hypoglycaemia is related to elevated serum ACE activity [15]. Serum ACE activity is, however, a highly heritable trait, with a large part of interindividual variability in ACE levels being due to genetic variation in the $A C E$ gene [16-20]. In this study we determined plasma SSAO activities in a large group of well-characterised patients with type 1 diabetes and investigated correlations with clinical parameters, as well as with components of the renin-angiotensin system (renin, angiotensinogen, ACE activity and genotype, angiotensin II receptor subtype $1[A T 1 R]$ and subtype $2[A T 2 R]$ genotype).

\section{Subjects and methods}

A total of 287 consecutive adult patients were recruited from the outpatient clinic at Hillerød Hospital, Denmark. They had all had type 1 diabetes mellitus for more than 2 years and did not have significant comorbidity beside late complications and hypertension, were not pregnant and not on haemodialysis. The presence of late complications was defined as existing retinopathy (untreated or laser-treated), and/or nephropathy (micro-albuminuria, proteinuria, or high serum creatinine), and/or neuropathy (senso-motor or autonomic, symptomatic or asymptomatic), stroke, myocardial infarction/angina or amputation as described previously [15]. The study was approved by the regional ethics committee and written informed consent was obtained from all patients.

Plasma SSAO activity was measured by a functional assay using benzylamine as substrate [21]. Serum ACE activity, $\mathrm{HbA}_{1} \mathrm{c}$ and $A C E I / D, A T 1 R(A T 1 R$ 1166A>C) and $A T 2 R(A T 2 R \quad 1675 A>G)$ genotypes were determined as previously reported $[15,22,23]$. Renin concentrations were measured by radioimmunoassay of generated angiotensin I, as was angiotensinogen in the presence of added excess of renin [24].

Standard statistical methods for descriptive and comparative analysis as well as for single and multiple regression analysis were used, employing the SPSS software package (version 10.0). In the backward stepwise multiple regression model with SSAO as the dependent variable, serum ACE activity, $A C E$ genotype, angiotensinogen, renin, $\mathrm{HbA}_{1} \mathrm{c}$, duration of diabetes, bodymass index and $A T 1 R$ and $A T 2 R$ genotype were included. A $p$ value of less than 0.05 (two-sided) was considered significant.

\section{Results}

The clinical characteristics of the cohort are shown in Table 1. We were able to obtain most, but not all data for all the patients. A few are missing, for example the presence or

Table 1 Complications and medication of the total group of patients

\begin{tabular}{|c|c|c|}
\hline Complication/medication & Number of patients $(n)$ & Percentage $(\%)$ \\
\hline \multicolumn{3}{|l|}{ Retinopathy } \\
\hline No & 126 & 45.0 \\
\hline Simplex & 107 & 38.2 \\
\hline Laser-treated & 47 & 16.8 \\
\hline \multicolumn{3}{|l|}{ Nephropathy } \\
\hline No & 194 & 72.1 \\
\hline Microalbuminuria & 50 & 18.6 \\
\hline Proteinuria & 20 & 7.4 \\
\hline High serum creatinine & 5 & 1.9 \\
\hline \multicolumn{3}{|l|}{ Senso-motor neuropathy } \\
\hline No & 184 & 65.5 \\
\hline Asymptomatic & 64 & 22.8 \\
\hline Symptomatic & 33 & 11.7 \\
\hline \multicolumn{3}{|l|}{ Autonomic neuropathy } \\
\hline No & 151 & 83.4 \\
\hline Symptomatic & 30 & 16.6 \\
\hline \multicolumn{3}{|l|}{ Stroke } \\
\hline No/yes & $281 / 5$ & $98.3 / 1.7$ \\
\hline \multicolumn{3}{|c|}{ Myocardial infarction/angina } \\
\hline No/yes & $271 / 15$ & $94.8 / 5.2$ \\
\hline \multicolumn{3}{|l|}{ Amputation } \\
\hline No/yes & $282 / 4$ & $98.6 / 1.4$ \\
\hline \multicolumn{3}{|l|}{ Hypertension } \\
\hline No/yes & $230 / 55$ & $80.7 / 19.3$ \\
\hline \multicolumn{3}{|l|}{ Medication } \\
\hline ACE-inhibitors no/yes & $227 / 60$ & $79.1 / 20.9$ \\
\hline ARB no/yes & $276 / 11$ & $96.2 / 3.8$ \\
\hline $\mathrm{CaCB}$ no/yes & $255 / 14$ & $94.8 / 5.2$ \\
\hline BB no/yes & $281 / 6$ & $97.9 / 2.1$ \\
\hline Diuretics no/yes & $259 / 28$ & $90.2 / 9.8$ \\
\hline
\end{tabular}

$A R B$ Angiotensin II-receptor blocker, $C a C B$ Calcium channel blocker, $B B$ Beta-blocker 
Table 2 Correlations of semicarbazide-sensitive amine oxidase in univariate analyses

\begin{tabular}{lrc}
\hline Parameter & $r$ value & $p$ value \\
\hline ACE activity & 0.246 & 0.001 \\
Duration of diabetes & 0.175 & 0.003 \\
$\mathrm{HbA}_{1} \mathrm{c}$ & 0.161 & 0.007 \\
Body mass index & -0.141 & 0.020 \\
Angiotensinogen & -0.187 & 0.002 \\
Renin & 0.138 & 0.020 \\
\hline
\end{tabular}

absence of autonomic neuropathy, which was investigated in only about two thirds of patients. Plasma SSAO activity in the total group of diabetic patients was two-fold higher than in normal control subjects ( $693 \pm 196$ vs $352 \pm 102 \mathrm{mU} / \mathrm{l}$; $p<0.001)$ [21]. In the group with late complications, plasma SSAO activity was higher than in the group without late complications $(727 \pm 202$ vs $627 \pm 164 \mathrm{mU} / 1, p<0.001)$. Patients with hypertension had higher plasma SSAO activity than normotensive patients $(782 \pm 236$ vs $671 \pm 180 \mathrm{mU} / \mathrm{l}$, $p<0.001)$, and the 60 patients treated with ACEI had higher plasma SSAO activity than those not on ACEI ( $786 \pm 218 \mathrm{vs}$ $668 \pm 183 \mathrm{mU} / 1, p<0.0001)$.

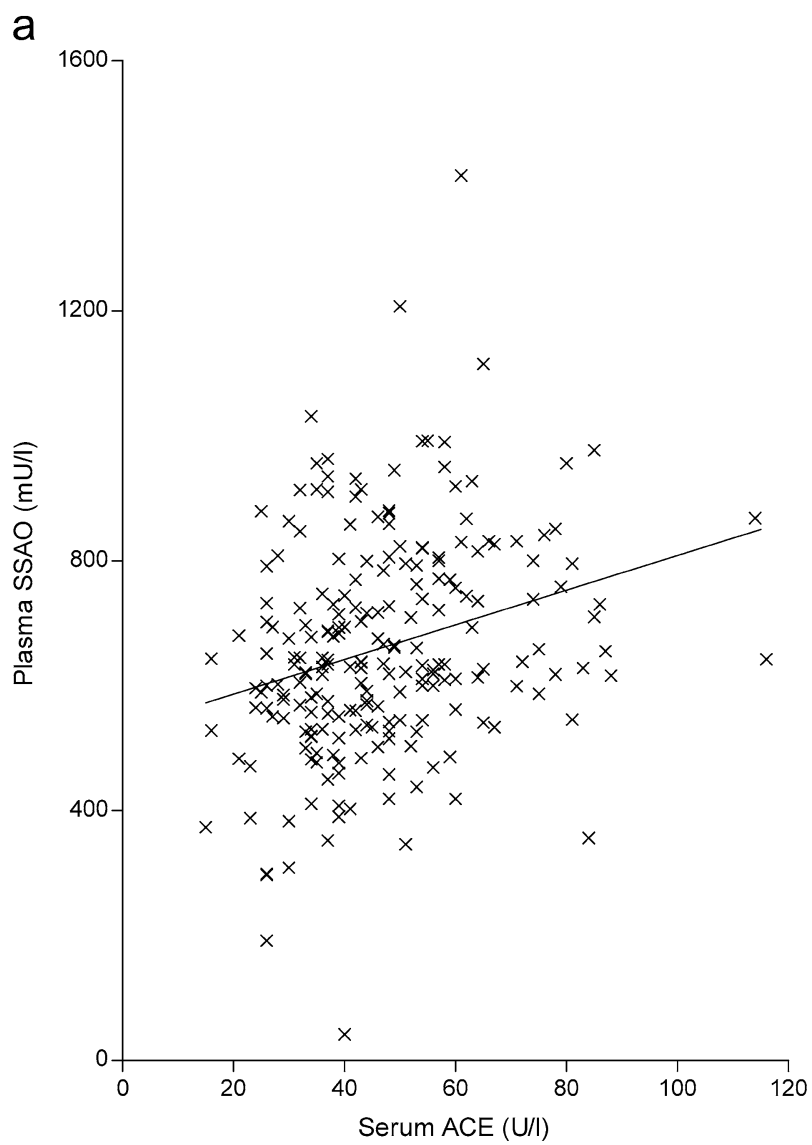

Fig. 1 Correlation between plasma semicarbazide-sensitive amine oxidase (SSAO) and serum ACE activities in all patients not on angiotensin-converting enzyme inhibitor or angiotensin receptor block-
Univariate regression analysis of the data of all patients showed plasma SSAO activity to be positively correlated with serum ACE activity (Table 2). After exclusion of patients on ACEI and angiotensin receptor blocker (ARB) therapy, the correlation persisted $(r=0.27, p<0.001$; Fig. 1a). Positive correlations were also found with duration of diabetes, $\mathrm{HbA}_{1} \mathrm{c}$ and renin, while negative correlations were found with body mass index and angiotensinogen. No correlations with $A T 1 R$ and $A T 2 R$ genotypes were found. No overall correlation was found between plasma SSAO activity and $A C E$ genotype ( $p=0.172$; Table 3 ). In a bivariate regression analysis including all patients not treated with ACEI or ARB, serum ACE activity and $A C E$ genotype were both predictors for plasma SSAO activity $(r=0.39, p<$ $0.001)$, with standardised beta coefficients of respectively 0.47 and -0.35 (Table 4). Thus, within the three separate genotypes a stronger correlation was found between plasma SSAO and serum ACE activities (Fig. 1b, Table 3) than in the overall regression analysis disregarding genotype.

In a backward stepwise multiple regression model including patients not treated with ACEI or ARB and entering 11 relevant parameters (serum ACE activity, $A C E$ genotype, angiotensinogen, renin, $\mathrm{HbA}_{1} \mathrm{c}$, duration of diabetes, hypertension, late complications, body mass index and $A T 1 R$ and $A T 2 R$ genotypes), the subsequent removal of non-signifi-

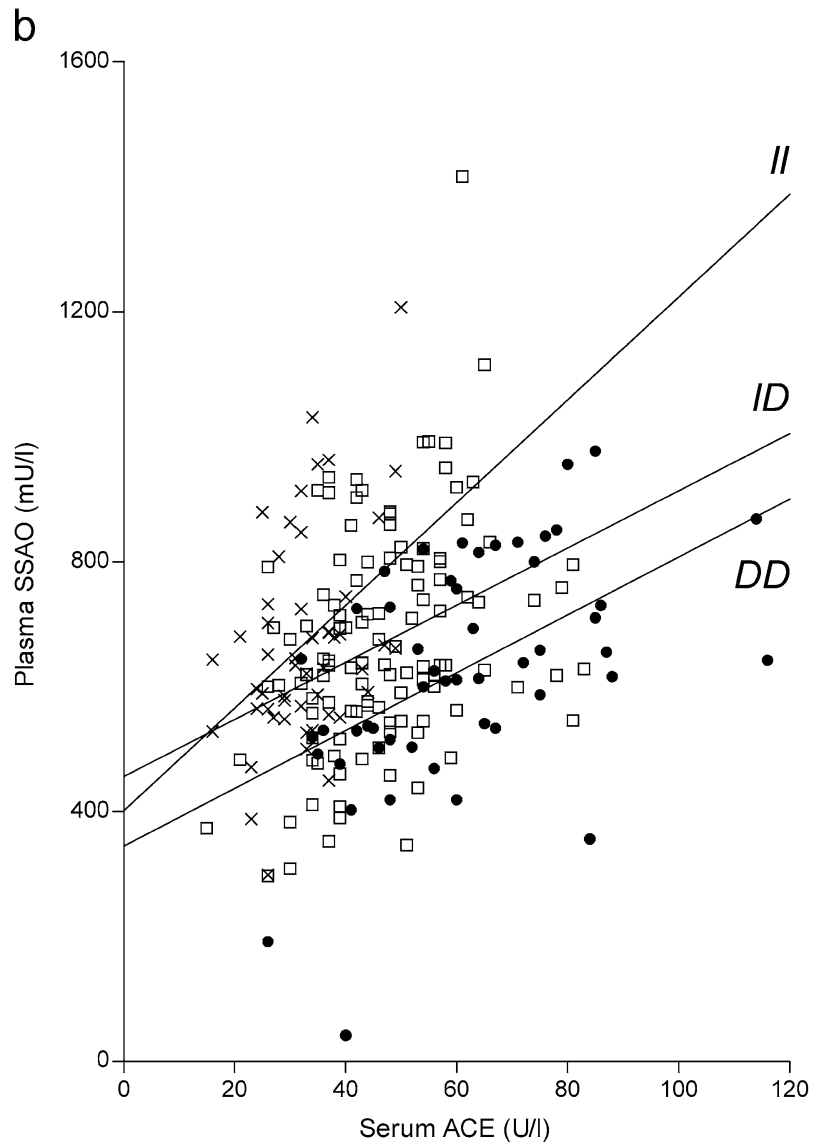

er treatment (a) and in the same patients, grouped according to $A C E$ $I / D$ polymorphism (b). Key (b): crosses, II; squares, ID; circles, $D D$ 
Table 3 Semicarbazide-sensitive amine oxidase (SSAO) and ACE activities and their correlations according to $A C E I / D$ genotype

\begin{tabular}{lrllll}
\hline$A C E$ genotype & $\begin{array}{l}\text { Number } \\
(n)\end{array}$ & $\begin{array}{l}\text { SSAO } \\
(\mathrm{mU} / \mathrm{l})\end{array}$ & $\begin{array}{l}\text { ACE } \\
(\mathrm{U} / \mathrm{l})\end{array}$ & $r$ value & $p$ value \\
\hline$I I$ & 52 & $677 \pm 174$ & $33 \pm 8$ & 0.388 & 0.005 \\
$I D$ & 122 & $681 \pm 186$ & $47 \pm 13$ & 0.332 & 0.001 \\
$D D$ & 51 & $627 \pm 181$ & $61 \pm 19$ & 0.501 & 0.001 \\
\hline
\end{tabular}

Table 4 Correlations of semicarbazide-sensitive amine oxidase in multiple regression analyses

\begin{tabular}{|c|c|c|c|c|}
\hline Model & Parameter & Standardised beta & $r$ value & $p$ value \\
\hline \multirow[t]{3}{*}{ A } & $A C E$ genotype & -0.35 & & $<0.0001$ \\
\hline & Serum ACE activity & 0.47 & & $<0.0001$ \\
\hline & Overall & & 0.39 & $<0.0001$ \\
\hline \multirow[t]{4}{*}{$\mathrm{B}$} & $A C E$ genotype & -0.34 & & $<0.0001$ \\
\hline & Serum ACE activity & 0.44 & & $<0.0001$ \\
\hline & $\mathrm{HbA}_{1} \mathrm{c}$ & 0.14 & & 0.022 \\
\hline & Overall & & 0.42 & $<0.0001$ \\
\hline \multirow[t]{4}{*}{$\mathrm{C}$} & $\mathrm{HbA}_{1} \mathrm{c}$ & 0.19 & & 0.008 \\
\hline & Late complications & 0.16 & & 0.023 \\
\hline & Body mass index & -0.15 & & 0.035 \\
\hline & Overall & & 0.29 & $<0.0001$ \\
\hline
\end{tabular}

Model A: bivariate model with serum ACE activity and $A C E$ genotype. Model B: backward stepwise analysis including serum ACE activity, $A C E$ genotype, renin, $\mathrm{HbA}_{1} \mathrm{c}$, angiotensinogen, duration of diabetes, hypertension, late complications, body mass index and $A T 1 R$ and $A T 2 R$ genotypes. Model C: like model B but excluding serum ACE activity and $A C E$ genotype

cant variables resulted in serum ACE activity $(p<0.0001)$, $A C E$ genotype $(p<0.0001)$, and $\mathrm{HbA}_{1} \mathrm{c}(p=0.022)$ as the main predictors for plasma SSAO activity $(r=0.42, p<0.001)$ (Table 4). Excluding ACE activity and genotype, a similar multiple regression analysis resulted in $\mathrm{HbA}_{1} \mathrm{c}(p=0.008)$, late complications $(p=0.023)$ and body mass index $(p=$ $0.035)$ as the best predictors. However, this was at a far less significant level $(r=0.29, p=0.001)$ (Table 4).

\section{Discussion}

Although plasma SSAO is elevated in diabetes, the regulation of SSAO formation remains obscure. Our study showed a highly significant positive correlation between plasma SSAO and serum ACE activity. In fact, serum ACE activity was the most significant predictor of SSAO level in a multivariate analysis.

In contrast to the lack of knowledge of factors controlling SSAO, it is known that $30-40 \%$ of the variation in serum ACE activity in Caucasians is associated with the $I($ nsertion $) / D$ (eletion) polymorphism of the $A C E$ gene [14, $20]$. Thus $D$ allele carriers have higher ACE activity than $I$ allele carriers $[18,20]$. The exact significance of ACE activity level or genotype for the general renin-angiotensin system activity is not certain and angiotensin II concentrations are not influenced by $A C E$ genotypes [14]. However, the $A C E I / D$ genotype has been shown to determine bradykinin metabolism $[25,26]$. And while the $D D$ genotype has been associated with increased occurrence of cardiovascular complications in some studies, just as often such an association could not be found [27].

The overall positive correlation between plasma SSAO activity and serum ACE activity suggests that a common factor is involved in the regulation and expression of ACE and SSAO. The fact that there was no overall difference in plasma SSAO between the $A C E$ genotypes implies that the $A C E$ gene is not the factor in question. This is supported by the stronger positive correlation between ACE and SSAO activities and by the negative correlation between the $A C E$ genotype and SSAO in the multivariate analysis. This indicates that at a fixed ACE activity, SSAO as well as ACE activity receive a greater contribution from the unknown factor in the $I I$ genotype than in the $I D$ and $D D$ genotypes.

Both SSAO and ACE are ectoenzymes occurring in a membrane-bound and a soluble form. The relation between soluble and membrane-bound human SSAO is not firmly established, but experiments with transgenic mice and rats strongly suggest that the major source of soluble SSAO is membrane-bound SSAO from endothelial cells and adipocytes $[8,9]$. Thus, it seems likely that the soluble form is formed from membrane-bound SSAO by shedding, as is the case for ACE [7,28]. The correlation between plasma SSAO and serum ACE activities might therefore be explained by a common sheddase or secretase. A common regulatory factor in the production of the two enzymes might also be an explanation. In a recent study, however, Göktürk et al. [29] found a negative correlation between plasma SSAO and mRNA in transgenic mice with alloxan-induced diabetes and concluded that the increase in plasma SSAO in diabetes must be explained by post-transcriptional changes and not by an elevated transcription rate. A third possibility is the existence of two independent mechanisms, both driven by the pathophysiology of diabetes or its complications. In this respect the suggestion of Göktürk et al. [29] that the excess flux of glucose in diabetes may enhance glycosylation, which, by protecting proteins from degradation, may increase the life-span of SSAO, would be interesting, if such a mechanism operated for SSAO and ACE.

The positive correlation between serum ACE activity and plasma SSAO activity can also explain the higher SSAO levels in patients on ACEI therapy, which at first sight seems contradictory. However, treatment with enzyme inhibitors often leads to an increase in production of the enzymes, in an attempt to restore the pre-treatment condition. Serum ACE activity is a direct reflection of the amount of ACE protein under normal circumstances, but during ACEI treatment the protein is prevented from expressing its enzyme activity, resulting in low activity, but with the protein still present, and in fact, it has been shown that production of the ACE protein increases [30]. Thus, the higher plasma SSAO activity in subjects on ACEI therapy is in line with such elevated serum concentrations of ACE protein. 
As expected, plasma SSAO activity was strongly elevated in the total group of patients compared to non-diabetic controls. This elevation may be driven by hyperglycaemia, as we found a positive correlation between plasma SSAO activity and $\mathrm{HbA}_{1} \mathrm{c}$ in accordance with previous studies [10-13]. Importantly, $\mathrm{HbA}_{1} \mathrm{c}$ was the only predictor besides ACE activity and genotype in the full multiple regression analysis. This robust association is intriguing, as SSAO has been implicated in the glycation process, as suggested by the inhibitory effect of aminoguanidine (an SSAO inhibitor) on glycation and AGE formation [31].

Plasma SSAO was higher in patients with late complications than in those without, in agreement with earlier reports [10-13], as well as in patients with hypertension or on ACEI treatment, two groups which overlap to a large extent. However, when including serum ACE activity in the backward multiple regression model, late complications, hypertension, and ACEI treatment were removed from the model, indicating that these factors are not independently associated with plasma SSAO activity. This is in accordance with an earlier report that hypertension by itself is not associated with elevated plasma SSAO activity [1].

A negative correlation was found between body mass index and plasma SSAO, as we have reported previously in a mixed group of type 1 and type 2 diabetic patients [11]. The correlation remained significant in the multiple regression model without ACE activity, but disappeared in the full model. Previous papers have reported either no correlation in type 2 [12] or even a positive correlation, also in a mixed group of type 1 and type 2 patients [13]. Both sample size and differences between the two types of diabetes might play a role in this discrepancy.

In conclusion, we have demonstrated a strong positive correlation between plasma SSAO and serum ACE activity in type 1 diabetes suggesting that both enzymes are regulated by a common factor which is not the $A C E$ gene. We have shown that plasma SSAO is positively associated with level of glycaemic control, and confirmed that plasma SSAO activity is elevated, the more so in the presence of late complications, hypertension and ACEI therapy. The increasing evidence for SSAO having both deleterious effects in terms of cytotoxicity, AGE-formation, and oxidative stress $[1,3-5]$, and beneficial effects in terms of enhanced glucose uptake, proper formation of blood vessel walls, and anti-inflammatory functions $[2,6,9]$ suggests the importance of regulatory factors to keep SSAO activity within narrow limits. The elevation of SSAO in diabetes could thereby be an adverse as well as a beneficial factor. It is therefore important to investigate whether the selective SSAO inhibitors currently being developed have similar and additional beneficial effects on the progress of diabetic complications as has been established for ACEI. Furthermore, identification of the factor(s) upregulating both SSAO and ACE in diabetes may provide a new target for drugs in the prevention of diabetic complications.
Acknowledgements The study was funded by grants from the EFSD/JDRF/Novo Nordisk Programme for Research in Type 1 Diabetes, the Foundation of Harald Jensen and wife, the Foundation of Olga Bryde Nielsen, the Foundation of Region 3, and the Research Foundation of Frederiksborg County. U. Pedersen-Bjergaard was supported by a grant from Novo Nordisk A/S, Bagsværd, Denmark. The authors wish to thank research nurses Pernille Banck and Tove Larsen of the Department of Internal Medicine F, Hillerød Hospital, for skillful collection and management of data. Research technicians Merete Pedersen, Kamma Velin, Mette Wolf, and Georg Söletormos, MD, DMSc of the Research Unit, Department of Clinical Biochemistry, Hillerød Hospital are thanked for their cooperation. We also thank technician Hanne Damm, Department of Clinical Biochemistry, Herlev University Hospital, for analysis of ACE activity and genotype. The technical skills of Usha Bhaggoe and Angelique van der Houwen at the Hypertension Research Laboratory of the Department of Internal Medicine, Erasmus MC, in determining SSAO activities are greatly appreciated.

\section{References}

1. Boomsma F, Bhaggoe UM, van der Houwen AMB, van den Meiracker AH (2003) Plasma semicarbazide-sensitive amine oxidase in human (patho)physiology. Biochim Biophys Acta 1647:48-54

2. Smith DJ, Salmi M, Bono P, Hellman J, Leu T, Jalkanen S (1998) Cloning of vascular adhesion protein 1 reveals a novel multifunctional adhesion molecule. J Exp Med 188:17-27

3. Yu PH, Zuo D-M (1993) Oxidative deamination of methylamine by semicarbazide-sensitive amine oxidase leads to cytotoxic damage in endothelial cells. Diabetes 42:594-603

4. Yu PH, Zuo D-M (1997) Aminoguanidine inhibits semicarbazide-sensitive amine oxidase activity: implications for advanced glycation and diabetic complications. Diabetologia 40:12431250

5. Yu PH, Deng YL (1998) Endogenous formaldehyde as a potential factor of vulnerability of atherosclerosis: involvement of semicarbazide-sensitive amine oxidase-mediated methylamine turnover. Atherosclerosis 140:357-363

6. Enrique-Tarancón G, Marti L, Morin N et al (1998) Role of semicarbazide-sensitive amine oxidase on glucose transport and GLUT4 recruitment to the cell surface in adipose cells. J Biol Chem 273:8025-8032

7. Abella A, Garcia-Vicente S, Viguerie N et al (2004) Adipocytes release a soluble form of VAP-1/SSAO by a metalloproteasedependent process and in a regulated manner. Diabetologia 47: 429-438

8. Stolen CM, Yegutkin GG, Kurkijarvi R, Bono P, Alitalo K, Jalkanen S (2004) Origins of serum semicarbazide-sensitive amine oxidase. Circ Res 95:50-57

9. Göktürk C, Nilsson J, Nordquist J et al (2003) Overexpression of semicarbazide-sensitive amine oxidase (SSAO) in smooth muscle cells leads to an abnormal structure of the aortic elastic laminas. Am J Pathol 163:1921-1928

10. Boomsma F, Derkx FHM, van den Meiracker AH, Man in 't Veld AJ, Schalekamp MADH (1995) Plasma semicarbazide-sensitive amine oxidase activity is elevated in diabetes mellitus and correlates with glycosylated haemoglobin. Clin Sci 88:675-679

11. Boomsma F, van den Meiracker AH, Winkel S et al (1999) Circulating semicarbazide-sensitive amine oxidase is elevated in type 1 (insulin-dependent) and in type 2 (non-insulin-dependent) diabetes mellitus: in childhood type 1 diabetes already at first clinical diagnosis. Diabetologia 42:233-237

12. Garpenstrand H, Ekblom J, Backlund LB, Oreland L, Rosenqvist U (1999) Elevated plasma semicarbazide-sensitive amine oxidase (SSAO) activity in type 2 diabetes mellitus complicated by retinopathy. Diabetic Med 16:514-521 
13. Mészáros Z, Szombathy T, Raimondi L, Karádi I, Romics L, Magyar K (1999) Elevated serum semicarbazide-sensitive amine oxidase activity in non-insulin-dependent diabetes mellitus: correlation with body mass index and serum triglyceride. Metabolism 48:113-117

14. Danser AHJ, Schunkert H (2000) Renin-angiotensin system gene polymorphisms: potential mechanisms for their association with cardiovascular diseases. Eur J Pharmacol 410:303316

15. Pedersen-Bjergaard U, Agerholm-Larsen B, Pramming S, Hougaard P, Thorsteinsson B (2001) Activity of angiotensinconverting enzyme and risk of severe hypoglycaemia in type 1 diabetes mellitus. Lancet 357:1248-1253

16. Cambien F, Alhenc-Gelas F, Herbeth B et al (1988) Familial resemblance of plasma angiotensin-converting enzyme level: the Nancy study. Am J Hum Genet 43:774-780

17. Keavney B, McKenzie CA, Connell JM et al (1998) Measured haplotype analysis of the angiotensin-I converting enzyme gene. Hum Mol Genet 7:1745-1751

18. Rigat B, Hubert C, Alhenc-Gelas F, Cambien F, Corvol P, Soubrier F (1990) An insertion/deletion polymorphism of the angiotensin I-converting enzyme gene accounting for half the variance of serum enzyme levels. J Clin Invest 86:1343-1346

19. Tarnow L, Cambien F, Rossing P et al (1995) Lack of relationship between an insertion/deletion polymorphism in the angiotensin I-converting enzyme gene and diabetic nephropathy and proliferative retinopathy in IDDM patients. Diabetes 44:489-494

20. Agerholm-Larsen B, Tybjaerg-Hansen A, Schnohr P, Nordestgaard BG (1999) ACE gene polymorphism explains 30-40\% of variability in serum ACE activity in both women and men in the population at large: the Copenhagen City heart study. Atherosclerosis 147:425-427

21. Van Dijk J, Boomsma F, Alberts G, Man in 't Veld AJ, Schalekamp MADH (1995) Determination of semicarbazidesensitive amine oxidase in human plasma by high-performance liquid chromatography with fluorimetric detection. J Chromatogr $663: 43-50$
22. Jones A, Dhamrait SS, Payne JR et al (2003) Genetic variants of angiotensin II receptors and cardiovascular risk in hypertension. Hypertension 42:500-506

23. Hunt CCJ, Burley JE, Chapman CML, Beilby JP (1999) A highthroughput MS-PCR method on MADGE gels for ANG II type1 receptor A1166C polymorphism. Physiol Genomics 1:71-73

24. Derkx FHM, Stuenkel C, Schalekamp MPA, Visser W, Huisveld IH, Schalekamp MADH (1986) Immunoreactive renin, prorenin, and enzymatically active renin in plasma during pregnancy and in women taking oral contraceptives. J Clin Endocrinol Metab 63:1008-1015

25. Murphey LJ, Gainer JV, Vaughan DE, Brown NJ (2000) Angiotensin-converting enzyme insertion/deletion polymorphism modulates the human in vivo metabolism of bradykinin. Circulation 102:829-832

26. Brown NJ, Blais C Jr, Gandhi SK, Adam A (1998) ACE insertion/deletion genotype affects bradykinin metabolism. J Cardiovasc Pharmacol 32:373-377

27. Agerholm-Larsen B, Nordestgaard BG, Tybjaerg-Hansen A (2000) ACE gene polymorphism in cardiovascular disease: meta-analyses of small and large studies in whites. Arterioscler Thromb Vasc Biol 20:484-492

28. Eyries M, Michaud A, Deinum J et al (2001) Increased shedding of angiotensin-converting enzyme by a mutation identified in the stalk region. J Biol Chem 276:5525-5532

29. Göktürk C, Nordquist J, Sugimoto H, Forsberg-Nilsson K, Nilsson J, Oreland L (2004) Semicarbazide-sensitive amine oxidase in transgenic mice with diabetes. Biochem Biophys Res Commun 325:1013-1020

30. Boomsma F, de Bruyn JHB, Derkx FHM, Schalekamp MADH (1981) Opposite effects of captopril on angiotensin I-converting enzyme 'activity' and 'concentration': relation between enzyme inhibition and long-term blood pressure response. Clin Sci 60:491-498

31. Yu PH, Zuo DM (1997) Aminoguanidine inhibits semicarbazide-sensitive amine oxidase activity: implications for advanced glycation and diabetic complications. Diabetologia 40:12431250 